\title{
The Online Looking Glass: The Study of Self Esteem and Narcissism on Instagram within a Patriarchal and Collectivist Society
}

\author{
By Juliet Dinkha ${ }^{*}$, Charles Mitchell ${ }^{ \pm}$Bashar Zogheib ${ }^{*}$ \& \\ Aya Abdulhadi ${ }^{+}$
}

\begin{abstract}
Online social networking sites have revealed an entirely new method of impression management and self-expression. These user-generated social tools present a new and evolving medium of investigation to study personality and identity. The current study examines how narcissism and self-esteem are demonstrated on the social networking application Instagram. To frame our research, we utilized the Uses and Gratifications Theory, which explains why audiences consume mediated messages and how and why authors create usergenerated media (UGM). In this research our objective was to understand how and why users of Instagram in Kuwait were using the social media platform and how it related and impacted their self-esteem and how it revealed, if any, narcissistic personality traits. To do so, self-esteem and narcissistic personality self-reports were collected from 79 Instagram users in Kuwait and we also followed and analyzed their Instagram accounts. In our analysis, these participants' profiles were coded on self-promotional content features based on their Instagram photos and captions posted on their Instagram accounts. By probing the relationship between this new medium, we can begin to understand the relationship amongst technology, culture, and the self.
\end{abstract}

Keywords: social media, Kuwait, Instagram, self-esteem, narcissism, social networking

\section{Introduction}

The influence of mass media on its audience has been the subject of longstanding debate since the introduction of radio and TV as entertainment and information media in the early $20^{\text {th }}$ century (Dominick 2009). Since this time, media scholars have been looking for ways to study media and to ascertain what detrimental effects they have on their audience including but not limited to the cultivation effect, introducing a young audience to sexual and violent images, presenting unrealistic body images, creating aggressive modelling behaviors and desensitization to violence that can come from mass media consumption of TV, film and even video games (Murray 2008, Perse and Lambert 2016, Dominick

\footnotetext{
*Associate Professor, American University of Kuwait, Kuwait.

${ }^{ \pm}$Independent Researcher, Kuwait.

"Chair, Math and Natural Sciences Department, American University of Kuwait, Kuwait.

${ }^{+}$Independent Researcher, Kuwait.
} 
2009). TV has been at the forefront of these studies as statistics indicate that children will spend more time in front of the TV than they will sleep by the time they are 18. Furthermore, by the time children are 18, they will have consumed more than 200,000 acts of television violence (Dominick 2009). Along this line, it is often the significance of the influence of mass media on youth that has been the most widely studied and debated. Moreover, early scholars often focused on TV's violent effects with often polarizing conclusions. Most notably, in 1961, Albert Bandura published his seminal work on children's modelling behaviors after they watched adults engaging in violent activities on a video monitor (Black and Newman 1995, Seawell 1998, Murray 2008, Dominick 2009, Fisher et al. 2009, Dinkha et al. 2014). The finding of this study indicated that people learn through imitation, modeling, and observing. Additionally, according to Bandura, people can learn through reward and punishment (Bandura et al. 1961).

Since the rise of the Internet age in early 1990s, scholars have been carrying out research on how the Internet influences its audience given the propensity for television to affect its viewers. During the last several decades, the studies into Internet consumption have centered on political participation, democratic mobilization and the most recently the concept of cyber bullying. For the fields of psychology and mass communications, there remains a gap in the research realm for the study of self-esteem, self-perception; and how these variables relate to the concept of narcissism within user-generated media, specifically social media. In our study, we decided to fill this need and investigate the relationships amongst narcissism, self-esteem and social media because, social media users have been increasingly engaging in excessive and sometimes addictive use of social networking platforms (O'Keeffe and Clarke-Pearson 2011). We opted to focus on the Middle East due to the limited research on this topic in the region and given that the cultural nuances could provide opportunities for additional inquires. Furthermore, we are researchers from Western and Eastern backgrounds who live in Kuwait. Another reason we decided on this topic is because Arabian Gulf countries have some of the highest concentrations of social media consumption in the world; and there remains a gap in the research on this region on the subject matter (Maarefi 2013). Furthermore, the Middle East is comprised of collectivist and patriarchal societies and would allow us the chance to discover if the authentic self is expressed in social networking given the need for individuals in the Arab world to often save face and uphold cultural mores and norms even during times of online engagement (Maarefi 2013). As a country with one of the largest penetrations of social media usage among youth and young adults in the Middle East and the world (Maarefi 2013), Kuwait provides the optimal platform for an interdisciplinary study encompassing mass communications and psychology on the relationships among social media, self-esteem and narcissism.

Moreover, Kuwait being a patriarchal society with different social mores for both men and women would provide additional research opportunities to ascertain if this variable has an affect on how males and females consume and utilize social media, including females being their authentic selves online versus adhering to gender roles proscribed by societal norms (Tétreault and Al-Mughni 1995, Tétreault 2001, Dinkha et al. 2008, Olimat, 2009). 


\section{Uses and Gratification Theory}

The Uses and Gratification Theory (UGT) is the principal paradigm exploited to frame our research. We decided up on this theory as it provides the most robust and relevant model to our key reasons for inquiry which are to understand how and why Instagram users in Kuwait are utilizing the platform and specifically what it says about their self-esteem and narcissism.

UGT was developed primarily for and is employed in the field of the mass communication theory and states audiences choose mediate messages to satisfy their needs. The theory serves scholars as a guide to assess and evaluate audience reasons for consuming and accessing media. Specifically, UGT provides us with the personal motivations as to why and how people use mass media (Rubin 2002, Stafford et al. 2004, Shao 2009, Urista et al. 2009).

Traditionally, UGT has been exploited to study audience behaviors with respect to consumption of radio, television and cable TV. In the digital age, however it has already been exploited as model to gauge audience usage of news media channels because it concedes, acceptance, uses, and creation of recent technologies and messages. In the era of new media, UGT has been purposeful for inquiry into understanding audiences and users' satisfaction with Internet based platforms: those noted for being highly interactive, flexible and constantly evolving. It further helps to understand and study motivations of (User Generated Media) UGM that is endemic in social media platforms (Stafford et al. 2004, Shao 2009).

McQuail (1983) identified four categories for why people select media: information, personal identity, integration and social interaction and lastly, entertainment. Recently however, media scholars have placed UGT into two principal categories that exemplify why audiences typically use the Internet: information and entertainment. Entertainment tells us that people seek messages on the Internet as they do with other forms of media such as movies and TV, often seeking out messages that will lift their mood, scare them or provide sexual arousal. Despite the tremendous benefits of entertainment seeking, information too is vital and is linked to the idea that an individual wants to exploit media to create awareness of themselves, others or the world. More typically and more simply put, UGT suggests that the utilization of media offers some form of gratification and helps us to decipher motivations behind consumption and creation of media, including related outcomes such as consequences or benefits (Shao 2009, Sheldon and Bryant 2016). Matsuba (2006) tell us there is a third category, interpersonal communication, which emphasizes the desires for individuals to utilize the Internet to fulfill relational needs.

Since the purpose of our research is understand what the UGM-framed social media platform Instagram tells us about self-esteem and narcissism, then UGT serves as the most applicable model to guide our research. For example, users routinely monitor their own followers' comments, likes and feedback as an indication of how well they are doing for the goal of receiving positive reinforcement (Gentile et al. 2012, Sheldon and Bryant 2016). 
Additionally, research has indicated that a correlation also exists between narcissism and the amount of time spent editing selfies before posting on social media, which confirms desire to be perceived positively by followers. This illustrates that users are seeking out online engagement as a compensatory need to be recognized and to satisfy the need for interpersonal communication (Dominick 1999, Matsuba 2006, Urista et al. 2009, Sheldon and Bryant 2016). Before we progressed with our study; however, it was important for us to explore and to understand the two psychological terms and conditions which we are studying on Instagram: narcissism and self-esteem.

\section{Narcissism}

Psychologists describe narcissism as the egotistical preoccupation with the self, personal preferences, aspirations, needs, success, and how one is perceived by others (Lopez De Victoria 2008). Austrian psychoanalyst Otto Rank linked narcissism it to self-admiration and vanity. Psychoanalyst, Heinz Kohut (1968), originated the term narcissistic personality disorder. He suggested that narcissism allows people to suppress feelings of low self-esteem and develop their sense of self. In 1980, narcissistic personality disorder was recognized by the American Psychiatric Association's (APA) third edition of the Diagnostic and Statistical Manual of Mental Disorders (DSM-III) (Burgemeester 2013).

There is now a comprehensive body of scientific research that focuses on narcissism and it has become a more widely understand phenomenon. According to (Mayo Clinic 2017) narcissistic personality disorder is characterized by dramatic and emotional behavior and a polarizing range of symptoms: The disorder's symptoms may include believing that you are better than others and that you are special, being easily hurt and rejected, seeking constant praise and admiration, and having a fragile self-esteem. A narcissist has trouble handling criticism, and to make themselves feel better, they react with rage and will do their best to belittle others so they would appear to be in the right.

The behavior characterized as narcissistic injury posits that a narcissist is sensitive to criticism and perceives those who disagree with their point of view as a threat and may take criticism itself as some type of form of rejection. They also tend to detach emotionally in fear of another narcissistic injury, and they devalue the person from whom they received the negative critique (Deconstructingjezebel n.d.)

It is argued that narcissistic individuals use social media because they offer a highly controllable environment where users can exhibit complete control over the way they present themselves. Another reason narcissist is attracted to social media sites is due to the capacity to maintain shallow relationships as they would ordinarily prefer over deeper interpersonal ones (Sheldon and Bryant 2016). In contrast to all other social media platforms, the nature of Instagram shifts the focus of individuals toward the self, thus, self-promotion and an identity focus are prioritized over actual face-to-face relationships. On Instagram, posting selfies is commonplace and is an expression of individuality. In comparison to other social 
media sites, Instagram is relatively more intimate, in which people share personal images such as pictures taken in their homes; whereas with Twitter for example, the user is constrained by a Tweet with limited characters and pictures are not necessary (Bradford 2018).

\section{Self-Esteem}

As mentioned previously, the UGT would surmise that some of the reasons why individuals consume mediated messages such as social media because it reinforces behaviors and responses that can build positive self-esteem, including bolstering personal value and self-understanding (Gentile et al. 2012, Sheldon and Bryant 2016). Historically, self-esteem refers to a person's positive or negative evaluation of the self; that is, the extent to which an individual views the self as worthwhile and competent (Coopersmith 1967). According to one definition by Braden in 1969, there are three key components of self-esteem: Firstly, self-esteem is an essential human need that is vital for survival and normal healthy development. Secondly, self-esteem arises automatically from within, based upon a person's principles and consciousness. Thirdly, self-esteem occurs in conjunction with a person's thoughts, behaviors, feelings, and actions. Self-esteem is expressed differently from one person to another, since it is developed through subjective experiences and interpersonal relationships. For instance, failing to meet parental standards during childhood can contribute to lowering the person's self-esteem in the future (Coopersmith 1967).

Those who display low self-esteem view themselves pessimistically. If they experience failure of some sort for instance, in the form of romantic rejections, unsuccessful job experiences, or any form of criticism, they take it personally and feel as if the unfortunate string of events is confirming their opinion of their worth. Experts call this occurrence negative validation. A 2014 study published in the Journal of Personality and Social Psychology by researchers from the University of Waterloo and Wilfrid Laurier University, found people with low self-esteem generally do not prefer optimism and would rather believe the negative comments they think about themselves are true (Olson 2014).

Martha Beck is an American sociologist, life coach, best-selling author, and speaker who specializes in helping individuals and groups achieve personal and professional goals. In 2014, she published an article titled How to Handle the Narcissists in Your Life for O magazine. Under the section 'How to Tell Healthy Self-Esteem from Narcissism' the author explains that people with a healthy selfesteem seek ways to improve themselves and would invent a long list of attributes they want to improve if confronted with the question: In what ways do you think you need to grow or change? On the other hand, narcissists will claim that they have nothing to change because admitting that they are imperfect is a difficult idea for them to process or express (Beck 2003). 


\section{Virtual Communities \& Social Networking Sites}

Virtual communities such as social networking sites like YouTube, LinkedIn, Facebook and Instagram are used as social platforms to establish and sustain friendships, and communicate with friends, colleagues and relatives at long or short distances, which provide users a way to feel connected to other people and as valuable means of self-expression. It has been theorized that people use virtual communities or social networking sites (SNS) because they desire to experience an instant and personal connection to others and as means of seeking approval and support (Urista et al. 2009).

For instance, the popularity of social media platforms such as Facebook and YouTube can be correlated to the social interaction and self-gratification these virtual communities provide to the users as public conversations online can deliver a sense of intimacy and often build and sustain and personal relationships. The advantages of these online communities are that they allow like-minded people to find each other and to form ties based on similarities and common interests (Shao 2009, Urista et al. 2009). Likewise, it has been observed that people often engage in virtual communities because it provides them with a sense of fitting in and belonging (Shao 2009). Along this line, a new generation of social media savvy Internet denizens have emerged whose identities are based on content generation and their social media friends, connections and followers (Urista et al. 2009).

Davenport et al. (2014) assert that two types of social networking expressions exist: active usage and passive usage. Active usage is displayed through engaging and creation of content on social media sites or website such as blogs, while passive usage is displayed through browsing and listening to content created by other users. On social media these two dynamics are typically on display where authors (active and frequent users) often create and share content with other followers (passive users) by posting likes, adding comments, saving favorites or sharing on their own accounts (Chan 2006). However, researchers observe that often causal browsers themselves became more active as they move from mere observer to participant by engaging in posting, sharing and liking, which are behaviors typical of active users (Shao 2009).

Given the flexible and customizable nature of social media Shao (2009) identifies UGM as being instrumental to these virtual communities because it enables users an important mode of self-expression. Self-expression on social media communities is offered in the form of videos, blogging, photos and other posts. The UGM allow authors to express and present their authentic selves or to share a side of themselves they see inside. These communities and platforms help the individual to project and craft an image of themselves to a larger audience than those in their immediate physical world (Dominick 1999, Smith 1999, Trammell and Keshelashvili 2005, Shao 2009). 


\section{Kuwait, the Internet and Social Media}

Kuwait is an Arab Muslim state situated in the Arabian Gulf with a population of around 3.9 million people, with $70 \%$ of the populous encompassing expatriate workers. Although Arabic is the national language, English is widely spoken. The urban population of Kuwait is $98 \%$ of the total inhabitants (CIA 2021).

Unlike most developing countries, Kuwait has a modern telecommunications infrastructure that is more in line with the standard found in a western European country than what is typically observed in most emerging economies. Kuwait was able to build upon this network because of its immense oil wealth and the need for increased communications following the Gulf War. Through a government commitment to building a modernized electronic communications network, mass communications has proliferated since the early 1990s, leading to a boom in media technologies and media consumption amongst the population (Wheeler 2000, Mitchell et al. 2014). This communications network has had an enormous impact on how the country assimilates and consumes mass communications. The State of Kuwait has encouraged the increase of media technologies in order "to provide for the Kuwaiti people's needs and to encourage their ambitions and aspirations and to develop, renew and exploit all available facilities to promote the well-being of the people" (Wheeler 2000, p. 433). Recognizing the power of mass communications, the state has further mandated the mass communications is necessary for the vitality of society and to promote Islam and Arabic culture to a global audience. Kuwaiti identity is shaped partly from technology and shared with the world through this technology (Wheeler 2000, Mitchell et al. 2014).

Kuwaitis, and especially Kuwaiti youth, were able to capitalize on Internet technology to expose themselves to foreign ideas due to the lack of censorship and the ability to circumvent controls with proxy servers (Wheeler 2003, Kaposi 2014). As Kaposi (2014) notes, the Internet is an important agent of socialization for young people and also provides them with a "sense of empowerment".

The contribution of the Internet in Kuwait has been revolutionary in that it has been proven to be an essential platform for liberation, personal sovereignty, the ideas of democracy and democratic reforms (Kaposi 2014). The Internet as a tool of social exchange has led to an explosion in blogging activity and as one respondent in Wheeler (2003) surmised at the time, it might have helped women to secure the right to vote.

Today, the Internet, and especially social media, has become the most important media vehicle for socializing with friends and family, keeping up with celebrity fandom, trend watching, gossiping, and exchanging modes of thought (Kaposi 2014, Wheeler 2003). Both Wheeler and Kaposi observed that the Internet is used by the youth to bypass traditional societal norms of dating and gender segregation as the youth readily use the Internet and social media to attract and to socialize with the potential dating partners. Furthermore, when surveyed many youths in Kuwait seemed to signify that Internet exchanges and posts allowed them to 'escape' and to be their authentic selves and they expressed a sense of self-liberation, which may be contrary to the roles they have to play in their everyday lives due to cultural mores (Kaposi 2014, Wheeler 2000, Wheeler 
2003). "The more taboo a topic, the more likely it is to show up in chat rooms. The more Kuwaiti society tries to separate the genders, the more likely the Internet will be used to transgress such boundaries" (Wheeler 2003, p. 14).

In Kuwait, the success of social media amongst the youth can be further attributed not only to the personal freedoms it provides but because it is perceived as hip and as an outlet to be fashionable and up-to-date on the newest fads (Kaposi 2014).

In consequence, the virtual social world has led Kuwait to exceptional high rates of usage of social platforms, such as Twitter, Snapchat and Instagram. According to Maarefi (2013) Kuwait is the Arabian Gulf country with the highest social media use per capita. Although no clear data exists about the number of Instagram users from Kuwait, simply searching for pictures hash tagged with Kuwait would present you with 19.1 million pictures. Markedly, that is approximately 1 million less than pictures tagged with USA, a country with tenfold Kuwait's population, on a search conducted on October 2014. Figure 1 illustrates the penetration of popular social media usage in Kuwait by age group.

Figure 1. Social Media Penetration in Kuwait by Age Group according to Ipsos MENA (2014)

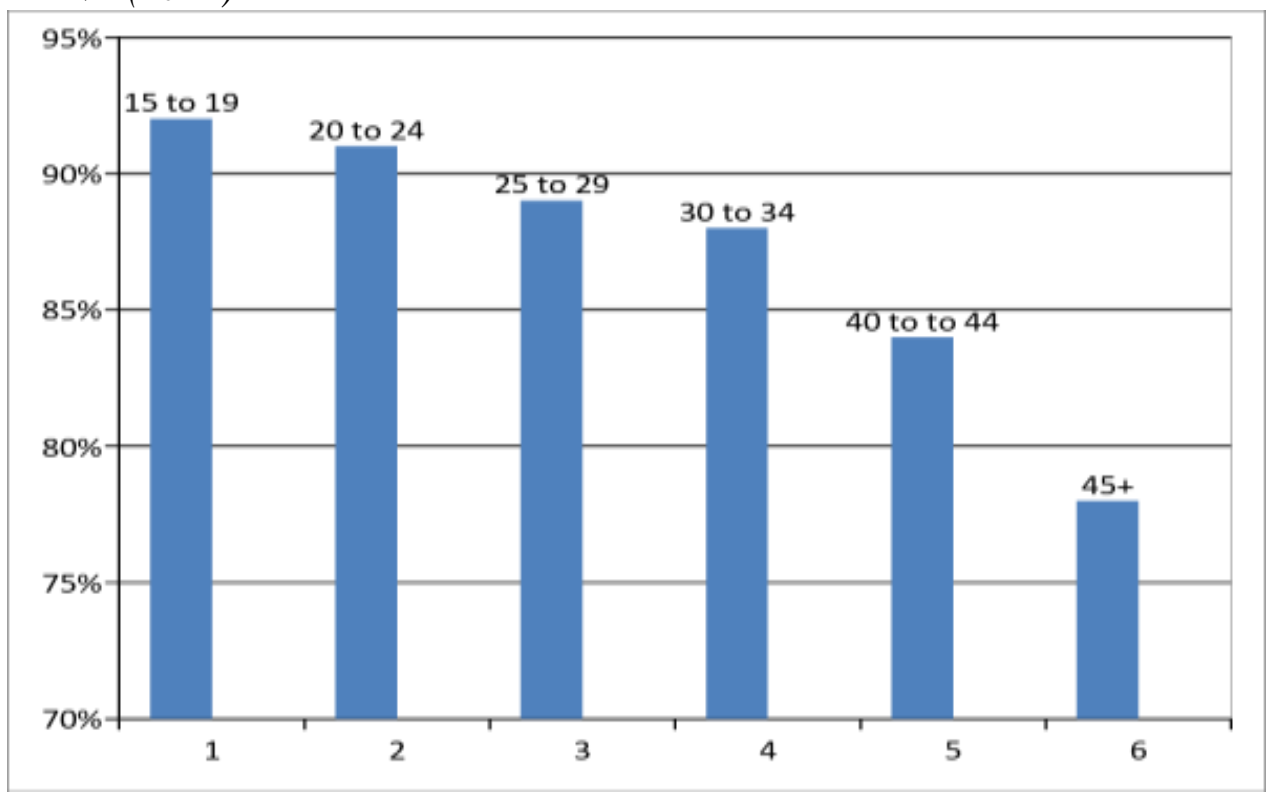

In Kuwait, with the popularity of Instagram came a new phenomenon of Instagram celebrities. An example of this is @ Ascia. Ascia is popular Kuwaitibased fashion blogger. With the explosion of Instagram in the country she now has 2.2 million followers when perused on July 2017, and charges upwards of $850 \mathrm{KD}$ $(2,550 \$)$ for one Instagram post Ascia's following is indicative of the high Instagram penetration in Kuwait when factoring in the country has a population of 3.9 million people (CIA 2021), and even when considering that many of her followers may well reside outside of the country. 


\section{Kuwait, Arab Culture, Gender and Social Media}

A Saudi study by Stanger et al. (2017) provided invaluable insight into social media habits of an Arabian Gulf country with a comparative cultural landscape to Kuwait. Kuwait is collectivist and patriarchal where family is regarded as a priority, and people define themselves in terms of the context in which they belong, such as by tribes, families from patriarchal lineage, and the country they belong to. Kuwaitis value modesty and honor greatly. Thus, the sharing of information on social media is linked to one's reputation within society. (Dinkha et al. 2008, Al-Jassar 2009, Dakhli et al. 2013, EEAS 2016, Stanger et al. 2017).

Women especially have greater limitations within Kuwait. Although the constitution guarantees equal protection for both men and women, a system of inequality remained intact for women within the society, women didn't receive full political and voting rights until 2005 (Olimat 2009, Donn and Al Manthri 2013). The prevalence of patriarchy is not only evident within the family unit but also extends to the patriarchal form of government. Kuwait has a long history of social controls placed on women, enacted based primarily on tradition and stringent interpretations of religious doctrine. As a result, men are the chief beneficiaries of state benefits that can include greater support and for parliamentary elections and cabinet posts, public sector employment, promotions and housing. Further restrictions on women can include limitations on choice of romantic partnerships and marriage. Additionally, both male and females grow up where education operates within a system of gender segregation, creating different socialization patterns for men and women (Tétreault and Al-Mughni 1995, Tétreault 2001, Dinkha et al. 2008, Olimat 2009).

In her 2006, dissertation that studied gender in Kuwait, Zaha Alsuwailan, noted that historically women in Kuwait were assigned specific gender roles, which meant they were relegated to second class status within society. In these traditional Arab homes, the father rules over the family and can make decisions on whether his daughter or his wife work and the types of education his daughters would receive (Alsuwailan 2006). In contemporary times, Kuwaiti women still face societal and legal obstacles because of gender such as marrying outside of their nationality, because these unions illustrate clear violations of cultural norms in a society where citizens have high social and political currency and children of Kuwaiti women and foreign men would inherent a foreign name and nationality.

In Kuwait, the family wealth, property, and decisions are passed on to the eldest male son. Women are still expected to adhere to social norms and to be deferential to men who are in positions of authority and to help with duties considered feminine such as household matters (Tétreault and Al-Mughni 1995, Tétreault 2001, Alsuwailan 2006).

In a Saudi Arabian study, participants indicated that they try to behave on social media in accordance with what is deemed acceptable by other group members and followers and adhere to social expectations. Moreover, most participants showed no interest in recognition and were uncomfortable revealing confidential information publicly. Participants preferred to keep a vague or secret identity on social media and avoided posting too much revealing information. The 
concern over maintaining privacy and pleasing other group members can result in the adoption of fake personalities on social media. The fake identity acts as a means for freedom of expression and communication with strangers in a society where mass communications are heavily controlled by the state. It was noted that women prefer fake accounts in order to protect their privacy online (Stanger et al. 2017).

With government restrictions controlling aspects of public media in Kuwait, this has propelled social media into the mainstream (Wheeler 2003). Our research delves into the dynamics of the incorporation of Instagram on a traditional and patriarchal society, namely Kuwait, and aims to investigate social media's influence on the individual's self-expression within this cultural setting. In our research, we explore social media as on online looking glass for self-esteem and narcissistic expression.

\section{Hypotheses}

1. The need to fulfill their relational and social needs in a collective society of Kuwait will lead to majority of our sample to qualify as frequent users of Instagram.

2. The activity level of users of Instagram in Kuwait will report narcissistic personality traits and high self-esteem.

3. Due to the patriarchal nature of Kuwait, male narcissistic respondents will outnumber female narcissistic respondents.

4. Narcissistic respondents are expected to self-promote and reinforce positive qualities about themselves through captions, pictures such as selfies, and photos of possessions than those of non-narcissistic respondents.

\section{Research Methods}

We utilized a convenient sample of 79 Instagram account owners within Kuwait out of a sample of 100 accounts, who were randomly recruited from Kuwait. The sample included both Kuwaiti and non-Kuwaitis. Their educational level ranged from high school to postgraduate levels. Their ages ranged from 1825 years. Please see Criteria for further explanation.

\section{Procedure}

Instagram users in Kuwait were identified and then approached through two different methods: (1) Some participants were identified and contacted through Instagram direct messaging and asked to participate in a study exploring their use of Instagram (2) Student researchers also approached students on campus of a private university in Kuwait and recruited students who had Instagram accounts and who expressed an interest in participating. 
The research team created an account on Instagram to gain and gauge participants for the study. We posted four posts including information about the study and who could participate. The selection process was restricted to participants who are in the age group of 18-25, residing in Kuwait, and completed the online survey sent via e-mail. The first post was about the research project with a brief description that we were studying usage of Instagram in Kuwait and encouraged people who were interested in the study to contact us via e-mail if they had questions. The second and third posts were to inform participants to accept our 'follow' requests on Instagram after completing the survey. The fourth post was about what participants need to do to participate in the research. Lastly, some of our research team members used their personal Instagram accounts to inform people about the study.

\section{Criteria}

All of those who were interested in participating were identified and selected based on whether they had an active Instagram account. Active users were placed into three categories: 1. High rate of postings (e.g., more than 3 a day, daily) 2 . Moderate rate of postings, (e.g., every other day, weekly) 3. Low rate of postings (e.g., biweekly, monthly). We found that the rate of postings did not correlate to self-esteem or narcissism, so all categories were combined in our statistics.

Upon agreeing to participate in this research study, participants were presented with a waiver form to sign if they consented to being followed on Instagram to have their page rated. Participants were also assured that all identifying information would be kept anonymous. Following their consent, participants were administered a four-part questionnaire. Upon completion, participants were immediately followed on Instagram and the process of rating and coding their pages began. The participants were aged between 18 and 25 years; they resided in Kuwait and had agreed and signed the consent form. The participants also completed the online survey sent to them via e-mail. Please see Tables 1, 2 and 3.

For the purpose of reliability and validity six raters ( 3 males and 3 females) who were in the same age category as our sample were used to evaluate five selfpromoting features of participants' Instagram: (a) The biography section, (b) The profile picture (c) The content of the first 15 pictures, (d) The frequency of uploading pictures, (e) Captions under photos.

For the purpose of this study, self-promotion was distinguished as any descriptive or visual information that appeared to attempt to persuade others about one's own positive qualities. For example, facial expression (e.g., striking a pose or making a face) and picture enhancement (e.g., using photo editing software) were coded in the profile picture and uploaded pictures. The use of positive adjectives (e.g., nice, sexy, funny), self-promoting mottos (e.g., 'I'm so glamorous I bleed glitter'), and/or positively descriptive hashtags were also noted.

Users whose native content was edited and enhanced prior to being posted, and frequently post on their native page with carefully chosen captions and elevated tone of voice are more likely to possess the characteristics of narcissism and high self-esteem compared to users who do not spend time to edit their content or self-promote in any measure. 


\section{Questionnaire Construction}

After agreeing to participate in this research study, Instagram owners were administered a brief four-part questionnaire. The first section required demographic information, including the participant's age and gender. The second section addressed their Instagram activity; it required respondents to indicate the number of times they checked their Instagram page per day and the time spent on Instagram per session. The remaining sections assessed two psychological constructs: selfesteem and narcissism. Prior to administering it to the participants, this questionnaire was distributed to 40 people for trial and feedback purposes.

Table 1. Categories Formulated to Rate Photos on Participants' Social Media Account, Instagram

\begin{tabular}{|c|c|}
\hline Measure & Variables \\
\hline Biography & $\begin{array}{c}\text {-Formal (Similar to CV) } \\
\text {-Informal } \\
\text {-No bio }\end{array}$ \\
\hline Links to other social media sites & $\begin{array}{l}\text {-Yes } \\
\text {-No }\end{array}$ \\
\hline Captions & $\begin{array}{l}\text {-Self promoting text } \\
\text {-Informal text } \\
\text {-No captions } \\
\end{array}$ \\
\hline Profile Picture & $\begin{array}{c}\text {-Real photo of the user } \\
\text {-Picture of other (celebrity etc.) } \\
\text {-No photo } \\
\end{array}$ \\
\hline Post rates & $\begin{array}{c}\text {-Frequent posts (Daily) } \\
\text {-Moderate (Weekly) } \\
\text {-Infrequently (monthly or more) }\end{array}$ \\
\hline Face visibility & $\begin{array}{c}\text {-Completely } \\
\text {-Partly } \\
\text {-Not visible }\end{array}$ \\
\hline Type of posts & $\begin{array}{c}\text {-Selfies } \\
\text {-Portraits } \\
\text {-Possessions } \\
\text {-Text } \\
\text {-Interests } \\
\text {-Landscapes } \\
\text {-Family, friends and pets }\end{array}$ \\
\hline Facial expression/pose & $\begin{array}{c}\text {-Model style pose } \\
\text {-Picture taken while doing an action (For example } \\
\text { playing a sport) } \\
\text {-Serious (CV style photo) }\end{array}$ \\
\hline Photo edits & $\begin{array}{c}\text {-Edited } \\
\text {-No Edits }\end{array}$ \\
\hline Location & $\begin{array}{l}\text {-Yes } \\
\text {-No }\end{array}$ \\
\hline
\end{tabular}

The Rosenberg Self-Esteem Scale was used to measure the participants' selfesteem. The original reliability of this scale is 0.72 . This measure has gained 
acceptable internal consistency and test-retest reliability, as well as convergent and discriminant validity. The Narcissism Personality Inventory (NPI-16) was also used. It is a short, efficient, and a valid mean to measure narcissism. It is composed of 16 questions.

In order to develop our rating criteria, we utilized categories from The Impression Management 2.0 The Relationship of Self-Esteem, Extraversion, SelfEfficacy, and Self-Presentation Within Social Networking Sites by Nicole C. Krämer and Stephan Winter (2008). The rating of the images was based on the following categories as illustrated below (Table 1). Additionally, a training session was conducted to train the coders for this project on how to apply the rating criteria and examine the profiles for the purpose of the study.

The difference is in our research versus Krämer and Winter (2008) is that we included Types of posts which include Selfies, portraits, possessions, text, interests, landscapes, family, friends and pets. These criteria were included due to the diverse types of photos Instagram users post on their accounts. In our research, we also included the post rate which is a measure of the frequency of posts. Captions under photos were also considered. For example, self-advocating hashtags, or selfpromoting photo descriptions. In the biography section the raters also looked at whether the users included links to other social media accounts. The similarity between the two scales is that they both examined the criteria for photo edits, location, face visibility, style of profile text, and facial expression pose.

\section{Results}

This study was administrated online where 79 participants from Kuwait were involved. Table 2 shows the number of female and male participants were almost identical. The $p$ value of 0.03 of the Chi-Square test (Table 4) showed that males are more narcissistic than females. The analysis found that no difference between genders in the number of bios they post. It was also found in our sample that no difference between people activities on Instagram and whether they are considered narcissistic or have low self-esteem.

Table 2. Gender Analysis of Participants

\begin{tabular}{|l|c|c|c|c|}
\hline & Frequency & Percent & Valid Percent & Cumulative Percent \\
\hline Female & 39 & 49.4 & 49.4 & 49.4 \\
\hline Male & 40 & 50.6 & 50.6 & 100.0 \\
\hline Total & 79 & 100.0 & 100.0 & \\
\hline
\end{tabular}


Table 3. Educational Level was not Related to Self-Esteem nor Narcissism

\begin{tabular}{|c|l|c|c|c|c|}
\hline \multicolumn{2}{|c|}{} & Frequency & Percent & Valid Percent & $\begin{array}{c}\text { Cumulative } \\
\text { Percent }\end{array}$ \\
\hline \multirow{6}{*}{ Valid } & Kuwait & 76 & 96.2 & 96.2 & 96.2 \\
\cline { 2 - 6 } & Other & 2 & 2.5 & 2.5 & 98.7 \\
\cline { 2 - 6 } & 3.00 & 1 & 1.3 & 1.3 & 100.0 \\
\hline \multirow{5}{*}{$\begin{array}{l}\text { less than } \\
\text { highschool }\end{array}$} & 1 & 1.3 & 1.3 & 1.3 \\
\cline { 2 - 6 } & $\begin{array}{l}\text { Some } \\
\text { highschool }\end{array}$ & 1 & 1.3 & 1.3 & 2.5 \\
\cline { 2 - 6 } & Highschool & 26 & 32.9 & 32.9 & 35.4 \\
\cline { 2 - 6 } & $\begin{array}{l}\text { some } \\
\text { college }\end{array}$ & 40 & 50.6 & 50.6 & 86.1 \\
\cline { 2 - 6 } & College & 9 & 11.4 & 11.4 & 97.5 \\
\cline { 2 - 6 } & postgraduate & 2 & 2.5 & 2.5 & 100.0 \\
\cline { 2 - 6 } & Total & 79 & 100.0 & 100.0 & \\
\hline
\end{tabular}

Table 4. Chi-Square Tests

\begin{tabular}{|l|c|c|c|c|c|}
\hline & Value & Df & $\begin{array}{c}\text { Asymp. Sig. } \\
\text { (2-sided) }\end{array}$ & $\begin{array}{c}\text { Exact Sig. } \\
\text { (2-sided) }\end{array}$ & $\begin{array}{c}\text { Exact Sig. } \\
\text { (1-sided) }\end{array}$ \\
\hline Pearson Chi-Square & $4.255^{\text {a }}$ & 1 & 0.039 & & \\
\hline Continuity Correction & 3.153 & 1 & 0.076 & & \\
\hline Likelihood Ratio & 4.387 & 1 & 0.036 & & \\
\hline Fisher's Exact Test & & & & 0.048 & 0.037 \\
\hline $\begin{array}{l}\text { Linear-by-Linear } \\
\text { Association }\end{array}$ & 4.201 & 1 & 0.040 & & \\
\hline N of Valid Cases & 79 & & & & \\
\hline
\end{tabular}

It was found from Table 5 that the number of female participants who scored below 15 was 37 and that of male participants was 33, while those who scored more than 15 were 7 male and 2 female participants. Those 9 participants are considered as displaying high self-esteem.

Table 5. Analysis of Self-Esteem

\begin{tabular}{|c|c|c|c|c|}
\hline & \multicolumn{2}{|c|}{ Self-Esteem } & \multirow{2}{*}{ Total } \\
\hline & & Below 15 & 15 or more & \\
\hline \multirow{2}{*}{ Gender } & Female & 37 & 2 & 39 \\
\hline & Male & 33 & 7 & 40 \\
\hline \multicolumn{2}{|c|}{ Total } & 70 & 9 & 79 \\
\hline
\end{tabular}

Table 6 shows that the number of female participants who scored 7 or above on the narcissistic scale was 8, which indicated narcissism. As for the male participants, those who score 9 or above are considered to have narcissistic tendencies. 12 male participants scored 9 or above. 
Table 6. Analysis of Narcissism

\begin{tabular}{|l|c|c|c|c|}
\hline \multicolumn{4}{|c|}{ Narcissism } & Total \\
\hline \multirow{3}{*}{ Gender } & \multirow{3}{*}{ Female } & Below 7 & 7 or more & \\
\cline { 3 - 5 } & & 31 & 8 & 39 \\
\cline { 3 - 5 } & \multirow{2}{*}{ Male } & Below 9 & 9 or more & \\
\cline { 3 - 5 } & & 28 & 12 & 40 \\
\hline
\end{tabular}

\section{Conclusion}

This research looked at the relationship between narcissism indicated in the Rosenberg self-esteem criteria (see Appendix) and the Narcissism Personality Inventory (NPI-16) (see Appendix) and narcissism expressed in the use of the social media web and application platform Instagram. Our results proposed no direct relationship between narcissism and self-esteem with gender on Instagram. However, the results show that respondents may score highly on the narcissism scale in the survey and low narcissism expression on Instagram or low on the narcissism scale in the survey and high on narcissism expression on Instagram. Additionally, results are consistent with the literature on gender differences with men scoring higher on the narcissism scale than woman (see Table 5).

The results of our research may seem on the surface to indicate that there are no correlations between narcissism, self-esteem, and Instagram. However, there could be myriad reasons why our results proved that there was no correlation: for example, Kuwait is a collectivist society and thusly the sense of self is shaped through a socialization process that puts the emphasis not on the self but on the family unit (Kluckhohn and Strodbeck 1961, Gay 1978, Leighton 1982, Al-Jassar 2009, Hofstede 1991, Berns 2013). In a collectivist society like Kuwait, the individual is constantly evaluating themselves based on their relationship to the family unit and to the larger society's collective identity in an effort to conform to group norms and not to stand out as an individual (Phinney 1991, Bernal and Knight 1993, Berns 2013).

As a matter of consequence, there is a strong propensity to confirm to the social mores and not to violate any of these norms even if they are not a true reflection of the authentic self. In Kuwait society, high standards of living and boasting of material wealth is one way in which narcissistic behavior would be apparent. Boasting would be a symptom of narcissism and pictures of material possessions were readily posted on the Instagram accounts across our sample. Nevertheless, narcissism was not widely identified when our sample was surveyed. So, in doing so, our sample may display narcissistic behaviors on Instagram but when surveyed they may fill in the NPI questionnaire with responses that are more aligned to societal norms. On the surface these responses would seem to preclude narcissism and would place emphasis on being humble, altruistic and selfless even if these qualifiqations are not emblematic of our respondents' authentic selves. Our hypotheses proposed that narcissists were expected to post self-promoting photos and post quotes and texts that are self-promoting or indicate high selfesteem; the users in the sample that we examined posted photos of their possessions 
often which are a sign of narcissistic behavior where prestige is attached to luxury possessions, which was found in Charoensukmongkol's (2016) study on narcissism.

In addition, our hypotheses suggested that narcissist respondents were expected to post more selfies, post more portraits, than non-narcissist respondents. Due to cultural factors such as modesty and cultural shame, certain individuals make their Instagram accounts private and then capitalize on this privacy to express their true self expressions to their close circle of friends, and who may be less judgmental and even supportive of their actions, and which may seem to cultural traditionalists as violating social norms. Congruently, these variables may explain the oddities found in our results.

The Western-centric nature of the NPI test, is also likely a causal factor that negated us finding the results as posited in our hypotheses. The questions on the NPI were composed in a manner in which those who are deemed narcissistic from a Western standpoint would self-identify through their answers. However, the socialization of Kuwait would impel many, if not most, to negate their narcissistic authentic selves and fill in questions that are more aligned with societal norms. For example, question one asks (a) "I would really like to be the center of attention" or (b) "It makes me uncomfortable to be the center of attention." In an individualistic society the standard respondent displaying narcissistic behaviors would check ' $a$ '; however, in Kuwait being the center of attention would be considered a deviation from cultural norms and so the respondent is more likely to check ' $b$ ' as their answer even if they are a narcissist. Question 2 asks (a) "I am no better or worse than most people "or (b) "I think I am a special person". Once again, according to the social norms of Kuwait even the most narcissistic person would likely check ' $b$ ' as their answer even if it is not reflective of the authentic self.

Accordingly, there is a propensity to abide by the norms, customs and traditions of the Kuwaiti society, even if these are not consistent with the inner authentic self (Dinkha et al. 2008). While our results for self-esteem reported were higher than narcissism, only nine participants scored more than 15, which is considered as displaying high self-esteem, and the rest were considered be within the range of low self-esteem.

We posit that the same phenomenon being that a Western-centric questionnaire encumbered participant from being honest about their true self-worth. For example, statement 1 reads, "On a whole I am satisfied with myself". Respondents may be more apt to choose to disagree or slightly disagree because it is more in line with cultural attitudes towards being humble. Correspondingly, statement 6 reads, "I do not have much to be proud of". Again, the socialization in society towards modesty may impel those to report 'disagree' or 'strongly disagree' even if those answers are not consistent with the inner self.

Several informal studies in blogs such as Psychology Today in the west presume that a high rate of selfies and photo editing are associated with an inflated self-esteem. While it may be true in the west, our study proves otherwise in Kuwait (Myers 2013). As we have postulated, our results could be correlated to the nature of the society itself.

Representations of self-esteem and narcissisim on social media could take different forms and shapes, and can evolve in new and emerging digital spaces, 
enabiling the users to generate different forms of expression. Content examined as part of this study is a reflection of how the users wanted to portray themselves on social media, which may not describe their true self. Therefore, our results did not support our hypotheses, that there would be a correlation between high self-esteem and narcissisitic traits.

\section{Limitations}

\section{The Number of Participants}

In the preliminary stage of this research paper, over a hundred surveys were disseminated. However, during the survey coding and Instagram rating processes, many of the participants were deemed invalid, due to not accurately completing the survey, or not accepting our 'follow request' during the process of Instagram accounts rating. There was also a challenge in dissemination of the survey because of Instagram doesn't allow links to be sent to other users with the questionnaires linking to a third-party site such as Survey Monkey or Google Docs.

Kuwait has very stringent defamation laws which cover online conversation and spreading of rumors. With recent bombing incident in the region, the government has toughened these measures and has warned both citizens and expatriates of the consequences of spreading rumors online (Duffy n.d., Toumi 2015). This climate leads to increased paranoia among social media users about what information they are sharing and with whom.

Many things might explain why the participants completed the survey but did not grant us access to their Instagram accounts. It could be that their accounts were inactive by the time we were ready to rate, or it could also be due to cultural reasons such as people not feeling comfortable with the idea of anonymous people perusing their personal pictures and posts. Regardless of the reasons, a viable way to counter this limitation in the future is to follow the participant's account concurrently with survey administering. This would be more efficient and would ensure access to the participants' Instagram accounts.

\section{Incorporating a Different Population}

When this research was at its infancy, it was attempted to also incorporate Saudi Arabia. However, since the researchers of this study are based in Kuwait, attempting to reach a large number of participants virtually was deemed to be a difficult task. Most of the successful surveys were administered in hard copies in a private university in Kuwait. Additionally, Saudi Arabia's population is even more conservative than Kuwait's, making it even harder to collect data when not residing directly in that country. In the future, when seeking to administer a survey in another country, utilizing a research partner who resides in that country would be a wise strategy. 


\section{References}

Al-Jassar MKA (2009) Constancy and change in contemporary Kuwait city: the sociocultural dimensions of the Kuwait courtyard and diwaniyya. ProQuest.

Alsuwailan ZF (2006) The impact of societal values on Kuwaiti women and the role of education. Unpublished Doctoral Dissertation. Knoxville, TN: University of TennesseeKnoxville.

Bandura A, Ross D, Ross SA (1961) Transmission of aggression through imitation of aggressive models. The Journal of Abnormal and Social Psychology 63(3): 575-582.

Beck M (2003, August) How to handle the narcissists in your life. Retrieved from: http:// www.oprah.com/omagazine/Martha-Beck-Self-Esteem-or-Narcissism. [Accessed 11 November 2019]

Bernal M, Knight G (Eds.) (1993) Formation and transmission among Hispanics and other minorities. New York: State University of New York Press.

Berns R (2013) Child, family, school, community: socialization and support. Belmont, CA: Wadsworth.

Black D, Newman M (1995) Television violence and children: its effects need to be seen in the context of other influences on children's mental health. BMJ: British Medical Journal 310(6975): 273-274.

Bradford A (2018, April) Everything you need to master Instagram Stories. Retrieved from: https://www.cnet.com/how-to/how-to-use-instag ram-stories/. [Accessed 2 April 2020].

Burgemeester A (2013, April) The history of narcissistic personality disorder. Retrieved from: http://thenarcissisticlife.com/the-history-of-narcissistic-personality-disorder/. [Accessed 24 June 2014]

Central Intelligence Agency - CIA (2021, April) The world factbook: Kuwait. Retrieved from: https://www.cia.gov/library/publications/the-world-factbook/ge os/ku.html/. [Accessed 24 June 2014]

Chan A (2006, February) Social interaction design case study: MySpace. Retrieved from: http://ww w. gravity7.com/G7_SID_case_myspace_v2.pdf. [Accessed 15 February 2019]

Charoensukmongkol P (2016) Exploring personal characteristics associated with selfieliking. Cyberpsychology: Journal of Psychosocial Research on Cyberspace 10(2).

Coopersmith S (1967) The antecedents of self esteem. San Francisco, CA: Freeman.

Dakhli M, Dinkha J, Matta M, Aboul-Hosson N (2013) The effect of culture and gender on coping strategies: an extension study. International Journal of Social Science 8(1): 87-98.

Davenport S, Bergman S, Bergman J, Fearrington M (2014) Twitter versus Facebook: exploring the role of narcissism in the motives and usage of different social media platforms. Computers in Human Behavior 32(Mar): 212-220.

Deconstructingjezebel (n.d.) What is narcissism: narcissistic injury. Retrieved from: http:// www.deconstructingjezebel.com/narcissistic-injury.html. [Accessed 17 March 2018]

Dinkha J, Abdulhamid S, Abdelhalim N (2008) How identity is constructed in Kuwait: analysis of four case studies. Psychology Journal 5(4): 190-211.

Dinkha J, Mitchell C, Zogheib B (2014) Parental control: the relationship amongst parental supervision, education, income and children's viewing habits. American Journal of Humanities and Social Sciences 2(3): 157-170.

Dominick J (1999) Who do you think you are? Personal home pages and self-presentation on the world wide web. Journalism and Mass Communicatin Quarterly 76(4): 646658 . 
Dominick JR (2009) The dynamics of mass communication: media in the digital age. New York, NY: McGraw-Hill.

Donn G, Al Manthri Y (Eds.) (2013) Education in the broader Middle East: borrowing a baroque arsenal. Symposium Books Ltd.

Duffy M (n.d.) (2015, July) Media laws and regulations of the GCC countries: summary, analysis and recommendations. Doha Centre for Media Freedom. Retrieved from: http://www.dc4mf.org/sites/default/files/gcc_media_law_en_0.pdf. [Accessed July 13, 2015]

European External Action - EEAS (2016, July) EU relations with the Gulf Cooperation Council (GCC). Retrieved from: http://eeas.europa.eu/gulf_cooperation/index_en. htm. [Accessed 11 July 2020]

Fisher AF, Hill DL, Grube JW, Bersamin MM, Walker S, Gruber EL (2009) Televised sexual content and parental mediation: influences on adolescent sexuality. Media Psychol 12(2): 121-147.

Gay G (1978) Multicultural preparation and teacher effectiveness in desegregated schools. Taylor \& Francis Group 17(2): 149-156.

Gentile B, Twenge JM, Freeman EC, Campbell WK (2012) The effect of social networking websites on positive self-views: an experimental Investigation. Computers in Human Behavior 28(5): 1929-1933.

Hofstede G (1991) Culture and organizations: software of the mind. London: McGrawHill.

Ipos MENA (2014) Social media users who access social media daily, 2012-2013 [Graph]. Retrieved from: http://www.slideshare.net/mobile/IpsosMENA/digitalme dia-forum-d http://www.slideshare.net/mobile/IpsosMENA/digitalmedia-forum-d. [Accessed 15 August 2017]

Kaposi I (2014) The culture and politics of Internet use among young people in Kuwait. Cyberpsychology: Journal of Psychosocial Research on Cyberspace 8(3): Article 1.

Kluckhohn F, Strodbeck F (1961) Variations in value orientation. Evanston, Illinois: Harper \& Row.

Kohut H (1968) Narcissistic personality disorders: outline systematic approach, Psychoanal. Study Child 23(1): 86-113.

Krämer NC, Winter S (2008) Impression management 2.0: the relationship of self-esteem, extraversion, self-efficacy, and self-presentation within social networking sites. Journal of Media Psychology 20(3): 106-116.

Leighton L (1982) Lermontov: a study in literary-historical evaluation. The American Association for the Advancement of Slavic Studies 41(2): 380-381.

Lopez De Victoria S (2008, August) How to spot a narcissist. Retrieved from: https://psy chcentral.com/blog/how-to-spot-a-narcissist\#1. [Accessed 24 June 2020]

Maarefi S (2013, July) KUNA: Social media gaining more leverage in Kuwait, needs optimization experts. Retrieved from: https://www.kuna.net.kw/ArticleDetails.Aspx? id $=2322334 \&$ language $=e n$. [Accessed 1 April 2021]

Matsuba K (2006) Searching for self and relationships online. Cyber Psychology \& Behavior 9(3): 275-284.

Mayo Clinic (2017, November). Narcissistic personality disorder. Retrieved from: https:// www.mayoclinic.org/diseases-conditions/narcissistic-personality-disor der/symptomscauses/syc-20366662. [Accessed 1 April 2021]

McQuail D (1983) Mass communication theory. $1{ }^{\text {st }}$ Edition. London: SAGE Publications.

Mitchell C, Dinkha A, Kononova A, Rashwan T, Matta M (2014) A body of dissatisfaction: a study of the effects of media imperialism in Kuwait. American Journal of Humanities and Social Sciences 2(1): 76-87. 
Murray JP (2008) Media violence the effects are both real and strong. American Behavioral Scientist 51(8): 1212-1230.

Myers DG (2013) The self in a social world. In Social Psychology, 40. $11^{\text {th }}$ Edition. New York, NY: McGraw Hill.

O'Keeffe GS, Clarke-Pearson K (2011) The impact of social media on children, adolescents, and families. Pediatrics 127(4): 800-804.

Olimat MS (2009) Women and politics in Kuwait. Journal of International Women's Studies 11(2): 199-212.

Olson S (2014, June) Misery loves company (so stop trying to cheer me up). Retrieved from: http://www.medicaldaily.com/low-self-esteem-sufferers-prefer-negative-com ments-so-dont-cheer-them-289936. [Accessed 26 June 2014]

Perse E, Lambert J (2016) Media Effects and Society. New York: Routledge.

Phinney JS (1991) Ethnic identity and self-esteem: a review and integration. Hispanic Journal of Behavioral Sciences 13(2): 193-208.

Rubin A (2002) The uses-and-gratifications perspective of media effects. In J Bryant, D Zillmann (eds.), Media Effects: Advances in Theory and Research, 525-548. $2^{\text {nd }}$ Edition. Hillsdale, NJ: Lawrence Erlbaum Associates, Inc.

Seawell M (1998) National television violence study. Volume 3. Thousand Oaks, CA: SAGE Publications.

Shao G (2009) Understanding the appeal of user-generated media: a uses and gratification perspective. Internet research 19(1): 7-25.

Sheldon P, Bryant K (2016) Instagram: motives for its use and relationship to narcissism and contextual age. Computers in Human Behavior 58(May): 89-97.

Smith M (1999) E-merging strategies of identity: the rhetorical construction of self in personal web sites. Doctoral Dissertation. Athens, OH: Ohio University.

Stafford TF, Stafford MR, Schkade LL (2004) Determining uses and gratifications for the Internet. Decision sciences 35(2): 259-288.

Stanger N, Alnaghaimshi N, Pearson E (2017) How do Saudi youth engage with social media? First Monday 22(5).

Tétreault MA (2001) A state of two minds: state cultures, women, and politics in Kuwait. International Journal of Middle East Studies 33(2): 203-220.

Tétreault MA, Al-Mughni H (1995) Modernization and its discontents: state and gender in Kuwait. The Middle East Journal 49(3): 403-417.

Toumi H (2015, July) Kuwait to deport expatriates found to be behind rumours. Gulf News. Retrieved from: https://gulfnews.com/world/gulf/kuwait/kuwait-to-deportexpatriates-found-to-be-behind-rumours-1.1545514. [Accessed 1 April 2021]

Trammell K, Keshelashvili A (2005) Examining the new influencers: a self-presentation study of a-list blogs. Journalism \& Mass Communication Quarterly 82(4): 968-982.

Urista MA, Dong Q, Day KD (2009) Explaining why young adults use MySpace and Facebook through uses and gratifications theory. Human Communication 12(2): 215-229.

Wheeler D (2000) New media, globalization and Kuwaiti national identity. Middle East Journal 54(3): 432-444.

Wheeler D (2003) The Internet and youth subculture in Kuwait. Journal of ComputerMediated Communication 8(2). 


\section{Appendix}

\section{Rosenberg Self-Esteem Scale}

The scale is a ten-item Likert scale with items answered on a four-point scale - from strongly agree to strongly disagree. The original sample for which the scale was developed consisted of 5,024 High School Juniors and Seniors from 10 randomly selected schools in New York State.

Instructions: Below is a list of statements dealing with your general feelings about yourself. If you strongly agree, circle SA. If you agree with the statement, circle A. If you disagree, circle D. If you strongly disagree, circle SD.

1. On the whole, I am satisfied with myself.

2. At times, I think I am no good at all.

$\begin{array}{llll}\text { SA } & \text { A } & \text { D } & \text { SD } \\ \text { SA } & \text { A } & \text { D } & \text { SD } \\ \text { SA } & \text { A } & \text { D } & \text { SD } \\ \text { SA } & \text { A } & \text { D } & \text { SD } \\ \text { SA } & \text { A } & \text { D } & \text { SD } \\ \text { SA } & \text { A } & \text { D } & \text { SD } \\ & & & \\ \text { SA } & \text { A } & \text { D } & \text { SD } \\ \text { SA } & \text { A } & \text { D } & \text { SD } \\ \text { SA } & \text { A } & \text { D } & \text { SD } \\ \text { SA } & \text { A } & \text { D } & \text { SD }\end{array}$

Scoring: $\mathrm{SA}=3, \mathrm{~A}=2, \mathrm{D}=1, \mathrm{SD}=0$. Items with an asterisk are reverse scored, that is, $\mathrm{SA}=0$, $A=1, D=2, S D=3$. Sum the scores for the 10 items. The higher the score, the higher the self-esteem.

The scale may be used without explicit permission. The author's family, however, would like to be kept informed of its use:

The Morris Rosenberg Foundation c/o Department of Sociology University of Maryland 2112 Art/Soc Building

College Park, MD 20742-1315 References

References with further characteristics of the scale:

Crandal R (1973) The measurement of self-esteem and related constructs. In JP Robinson, PR Shaver PR (eds.), Measures of Social Psychological Attitudes, 80-82. Revised Edition. Ann Arbor: ISR.

Rosenberg M (1965) Society and the adolescent self-image. Princeton, NJ: Princeton University Press.

Wylie RC (1974) The self-concept. Revised Edition. Lincoln, Nebraska: University of Nebraska Press.

NPI-16

Read each pair of statements below and place an " $X$ " by the one that comes closest to describing your feelings and beliefs about yourself. You may feel that neither statement describes you well but pick the one that comes closest. Please complete all pairs. 
1 - I really like to be the center of attention

$2 \quad$ - It makes me uncomfortable to be the center of attention
- I I n no better or no worse than most people
- I think I am a special person

3 - Everybody likes to hear my stories

- Sometimes I tell good stories

$4 \quad$ - I usually get the respect that I deserve

- I Insist upon getting the respect that is due me

$5 \quad$ - I don't mind following orders

_ I I like having authority over people

6 - I am going to be a great person

- I hope I am going to be successful

7 - People sometimes believe what I tell them

- I can make anybody believe anything I want them to

8 - I expect a great deal from other people

- I like to do things for other people

$9 \quad$ - I like to be the center of attention

- I prefer to blend in with the crowd

10 - I am much like everybody else

- I I am an extraordinary person

11 - I always know what I am doing

- $\quad$ Sometimes I am not sure of what I am doing

12 - I don't like it when I find myself manipulating people

- I I find it easy to manipulate people

13 - Being an authority doesn't mean that much to me

- People always seem to recognize my authority

14 - I know that I am good because everybody keeps telling me so

- When people compliment me, I sometimes get embarrassed

15 - I try not to be a showoff

- I I am apt to show off if I get the chance

16 - I am more capable than other people

- There is a lot that I can learn from other people 
NPI-16 Key: Responses consistent with narcissism are shown in bold.

$1 \quad$ - I really like to be the center of attention

- It makes me uncomfortable to be the center of attention

2 - I am no better or nor worse than most people

_ I think I am a special person

$3 \quad$ - Everybody likes to hear my stories

- Sometimes I tell good stories

$4 \quad$ - I usually get the respect that I deserve

- I I insist upon getting the respect that is due me

$5 \quad$ - I don't mind following orders

_ I like having authority over people

$6 \quad$ - I am going to be a great person

_ I hope I am going to be successful

$7 \quad$ - People sometimes believe what I tell them

_ I can make anybody believe anything I want them to

$8 \quad$ - I expect a great deal from other people

_ I like to do things for other people

$9 \quad$ - I like to be the center of attention

- I prefer to blend in with the crowd

10 - I am much like everybody else

- I am an extraordinary person

11 - I always know what I am doing

_ Sometimes I am not sure of what I am doing

12 - I don't like it when I find myself manipulating people

_ I I find it easy to manipulate people

13 - Being an authority doesn't mean that much to me

- People always seem to recognize my authority

14 - I know that I am good because everybody keeps telling me so

- When people compliment me, I sometimes get embarrassed

15 - I try not to be a showoff

- I am apt to show off if I get the chance

16 - I am more capable than other people

- There is a lot that I can learn from other people 
Scoring: compute proportion of responses consistent with narcissism.

Background: The NPI-16 items are drawn from across the dimensions of Raskin and Terry's (1988) 40-item measure. Relevant references are noted below:

Ames DR, Rose P, Anderson CP (2006) The NPI-16 as a short measure of narcissism. Journal of Research in Personality 40: 440-450.

Raskin R, Terry H (1988) A principal-components analysis of the narcissistic personality inventory and further evidence of its construct validity. Journal of Personality and Social Psychology 54: 890-902. 